\title{
NUMERICAL MODELING TO EVALUATE PILE HEAD DEFLECTION UNDER THE LATERAL LOAD
}

\author{
Kedar C. Birid ${ }^{1}$ \\ ${ }^{1}$ Assistant Manager, Toyo Engineering India Pvt. Ltd., Mumbai, Maharashtra, India, kedarbirid@ gmail.com
}

\begin{abstract}
The complex behavior of pile head deflection under the lateral load can be studied using various analytical methods and the softwares. Often the lateral pile load testing is carried out in the field to confirm the calculated lateral pile capacity. However, even with the use of sophisticated latest softwares, the accurate deflection of pile head cannot be estimated. Hence an attempt has been made in this paper to evaluate the pile head deflection using the field load-deflection data and the corresponding soil and pile properties. A preliminary mathematical model has been developed using a technique of dimensional analysis (DA) to evaluate pile head deflection under different pile diameters, different pile materials and varying soil conditions. The estimated pile head deflection using DA equation is compared with 14nos. of measured lateral pile load test results conducted at the site. It can be observed from this study that, the dimensional analysis can be used effectively to estimate the pile head deflection. More variables based on more field results can be introduced in the mathematical model to increase the accuracy in the estimation of pile head deflection.
\end{abstract}

Keywords: Pile head deflection, Lateral pile load, Dimensional analysis

\section{INTRODUCTION}

The pile foundations subjected to lateral loading involve complex soil structure interaction. There are several analytical methods and softwares are available to study the pile behavior. In spite of the availability of the latest techniques and softwares, it is invariably recommended to carry out the field pile load tests to understand the correct behavior of pile under the lateral loading. It would be therefore realistic if the pile behavior is modelled directly based on the field data on test piles. The parameters that affect the pile head deflection under the lateral loadings can be assigned with appropriate weightage depending on its contribution in deflecting the pile under lateral load. The author has attempted development of such mathematical model using dimensional analysis to assess its applicability in soil-structure interaction problem. The field test results of lateral pile head deflection under free head condition were processed using a mathematical tool of dimensional analysis to arrive at a correlation equation.

\section{NUMERICAL MODELING USING DIMENSIONAL ANALYSIS}

In physics and all science, dimensional analysis is the practice of checking relations between physical quantities by identifying their dimensions. The dimension of any physical quantity is the combination of the basic physical dimensions that compose it. Some fundamental physical dimensions are length (L), mass (M) and time (T). All other physical quantities can be expressed in terms of these fundamental physical dimensions. As examples, the dimension of the physical quantity speed is the distance (length/time) i.e. L/T or $\mathrm{LT}^{-1}$, and the dimension of the physical quantity force is "mass $\times$ acceleration" or "mass $\times($ length/time)/time" i.e. $\mathrm{ML} / \mathrm{T}^{2}$ or $\mathrm{MLT}^{-2}$.
Dimensional analysis is a proven mathematical solution to develop numerical models for various civil engineering problems such as reinforced concrete beams subjected to pure torsion [4], bearing capacity of footings in sand [5], estimation of phreatic line in earthen dams [6], determination of the corrected compressive strength of rock [2] and others. It was therefore decided to apply the same numerical technique for estimation of pile head deflection under the lateral loading in the present case.

The basis of dimensional analysis and the methodology has already been explained by Butterfield [3] and the current paper uses same notations and symbols.

The aim of dimensional analysis is to reduce the dimension space to a minimum in which the behavior of a specific system might be studied by combining and arranging systematically the assumed governing variables $(v)=\left(v_{1}, v_{2}\right.$, $\mathrm{v}_{3}, \ldots \ldots, \mathrm{v}_{\mathrm{n}}$ ) encompassing a total of $\mathrm{m}$ independent primary dimensions $\left(D_{p}\right)=\left(D_{1}, D_{2}, D_{3}, \ldots, D_{N}\right)$ into $N=(n-m)$ Dimensionless Groups (D.G.s), that are $\left(\pi_{1}, \pi_{2}, \pi_{3}, \ldots \ldots\right.$, $\left.\pi_{\mathrm{N}}\right), \mathrm{N}$ being less than $\mathrm{v}[2]$.

Here $\mathrm{D}=$ Diameter of pile in $\mathrm{m}$.

$\mathrm{E}_{\mathrm{p}}=$ Modulus of elasticity of pile material, $\mathrm{kN} / \mathrm{m}^{2}$

$\mathrm{E}_{\mathrm{s}}=$ Average modulus of elasticity of soil up to $5 \mathrm{~m}$

depth from the pile head, $\mathrm{kN} / \mathrm{m}^{2}$

$\mathrm{H}=$ Lateral load on pile head, $\mathrm{kN}$

$\mathrm{y}=$ Pile head deflection in $\mathrm{m}$.

Here, we have $v=\left\{D, E_{c}, E_{s}, H, y\right\}$, hence $n=5$

Writing the dimensions of the variables

$\{\mathrm{v}\}=\left[\mathrm{M}^{0} \mathrm{LT}^{0}, \mathrm{ML}^{-1} \mathrm{~T}^{-2}, \mathrm{ML}^{-1} \mathrm{~T}^{-2}, \mathrm{MLT}^{-2}, \mathrm{M}^{0} \mathrm{LT}^{0}\right], \mathrm{m}=3$, i.e. the number of repeating variables forming a set $\mathrm{Q}$ (i.e. $\mathrm{M}, \mathrm{L} \& \mathrm{~T})$.

Let $\mathrm{MLT}^{-2}=\mathrm{P}$ 
Therefore, $\mathrm{v}=\left\{\mathrm{L}, \mathrm{PL}^{-2}, \mathrm{PL}^{-2}, \mathrm{P}, \mathrm{L}\right\}$ and $\mathrm{m}=2$ (i.e. $\mathrm{P} \& \mathrm{~L}$ ).

The number of the dimensionless $\mathrm{Pi}$ - group is

$$
\mathrm{N}=(\mathrm{n}-\mathrm{m})=(5-2)=3
$$

now $\mathrm{R}=$ set of variables in $\mathrm{v}$ which have dimensions totally distinct from each other.

Therefore, $\mathrm{R}=\left\{\mathrm{D}, \mathrm{E}_{\mathrm{p}}, \mathrm{H}\right\}$

$Q$ is to be selected from $R$, therefore $Q 1=\left\{D, E_{p}\right\}$

$$
\begin{aligned}
& \mathrm{Q} 2=\{\mathrm{D}, \mathrm{H}\} \\
& \mathrm{Q} 3=\left\{\mathrm{E}_{\mathrm{p}}, \mathrm{H}\right\}
\end{aligned}
$$

Select any combination of Q e.g. Q1 $=\left\{D, E_{p}\right\}$

Therefore, the dimensionless groups are,

$$
\pi_{1}=\left\{D, E_{p}, E_{s}\right\}, \pi_{2}=\left\{D, E_{p}, H\right\}, \pi_{3}=\left\{D, E_{p}, y\right\}
$$

Therefore, represent $\pi_{1}$ as,

$\pi_{1}=\left(D^{\mathrm{a}}, \mathrm{E}_{\mathrm{p}}^{\mathrm{b}}, \mathrm{E}_{\mathrm{s}}^{\mathrm{c}}\right)$

It can be written in dimensional form as,

$\left[\mathrm{M}^{0} \mathrm{~L}^{0} \mathrm{~T}^{0}\right]=\left[\mathrm{M}^{0} \mathrm{LT}^{0}\right]^{\mathrm{a}} \times\left[\mathrm{ML}^{-1} \mathrm{~T}^{-2}\right]^{\mathrm{b}} \times\left[\mathrm{ML}^{-1} \mathrm{~T}^{-2}\right]^{\mathrm{c}}$

Comparing the indices of the Left Hand Side and the Right Hand Side, for M, L, \& T from the equation (2),

$$
\begin{aligned}
& M: 0=b+c \\
& \text { L: } 0=a-b-c \\
& T: 0=-2 b-2 c
\end{aligned}
$$

In order to generate relations of $\mathrm{a}, \mathrm{b} \& \mathrm{c}$ with respect to each other, select $b=1$

Now if $\mathrm{b}=1$, then $\mathrm{a}=0$ and $\mathrm{c}=-1$

Substituting the values in the equation (1) we get,

$$
\begin{gathered}
\pi_{1}=\left\{\mathrm{D}^{0}, \mathrm{E}_{\mathrm{p}}, \mathrm{E}_{\mathrm{s}}^{-1}\right\} \\
=\frac{E_{p}}{E_{s}}
\end{gathered}
$$

Similarly, $\pi_{2}=\left(\frac{E_{p} D^{2}}{H}\right)$ and $\pi_{3}=\frac{D}{y}$

Now, let $\pi_{1}=\varphi\left(\pi_{2}\right)$, where $\varphi$ is an unknown function.

Therefore, we can write,

$$
\pi_{1}=\beta_{1}\left(\pi_{2}\right)^{\beta_{2}}\left(\pi_{3}\right)^{\beta 3}
$$

Substituting the $\pi$ values in the equation (3)

$$
\frac{E_{p}}{E_{s}}=\beta_{1}\left(\frac{E_{p} D^{2}}{H}\right)^{\beta_{2}}\left(\frac{D}{y}\right)^{\beta_{3}}
$$

To find the values of constants $\beta_{1}$, and $\beta_{2}$ representative field test data have been selected based on field pile test results of pile no. 4 (see table 1) as follows;

Diameter of pile, $\mathrm{D}=0.45 \mathrm{~m}$

Modulus of elasticity of pile material, $\mathrm{E}_{\mathrm{p}}=27386127.88$ $\mathrm{kN} / \mathrm{m}^{2}$

Average modulus of elasticity of soil, $\mathrm{E}_{\mathrm{s}}=42000 \mathrm{kN} / \mathrm{m}^{2}$

Pls. note that, this value of $\mathrm{E}_{\mathrm{s}}$ is considered based on average of the top $5 \mathrm{~m}$ depth of soil from the pile head.

Lateral load on pile head, $\mathrm{H}=72.7 \mathrm{kN}$

Measured pile head deflection, $\mathrm{y}=2.66 \times 10^{-3} \mathrm{~m}$

Substituting these values in equation (4) we get

$$
652.05=\left[\beta_{1}(76281.85)^{\beta_{2}}(169.17)^{\beta_{3}}\right]
$$

In natural logarithmic form,

$$
6.4801=\left[\ln \beta_{1}+11.2421 \beta_{2}+5.1309 \beta_{3}\right]
$$

Solving equations (5) and (6) using trial and error we get,

$$
\beta_{1}=0.140, \beta_{2}=1.018 \text { and } \beta_{3}=-0.585
$$

Substituting the above values in equation (4) we get,

$$
y=\sqrt[-0.585]{0.14 E_{s} E_{p}^{0.018} D^{1.451} L^{-1.018}}
$$

This universal equation (7) can be used to estimate the pile head deflection for varying pile types, sizes, lateral loads and soil conditions.

\section{COMPARISON}

The comparison of the predicted pile head deflection using equation (7) is carried out with the field lateral load test deflection values. 14 nos. of pile lateral load tests have been carried out as per ASTM guidelines [1] across the globe as indicated in fig. 1 under the free head condition. The pile types comprised of continuous flight auger (CFA) piles, auger cast in place piles (ACIP), driven pretensioned hollow concrete (PHC) piles, driven cast-in-situ piles, driven steel pile and bored cast-in-situ piles of varying lengths.

The load-settlement data and the comparison of measured and calculated pile head deflection is presented in table 1 and chart 1. 


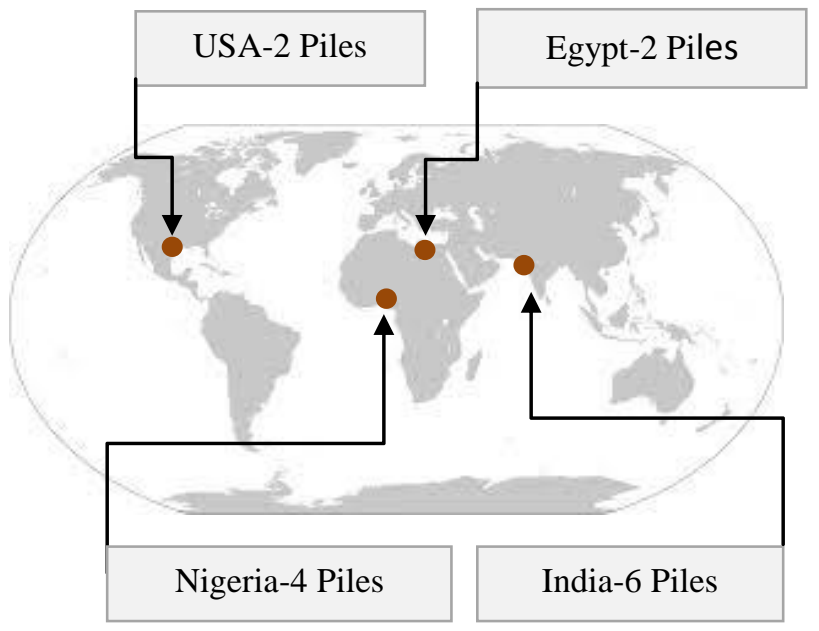

Fig -1: Extent of pile test data

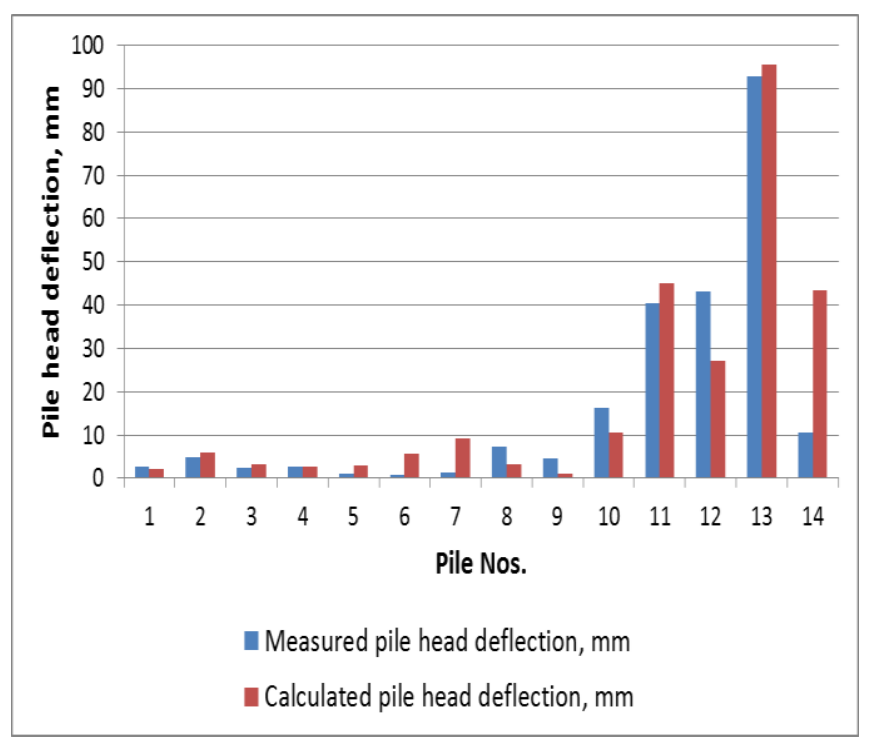

Chart -1: Pile head deflection-Measured Vs Calculated from equation (7)

It can be observed from this comparison that the $64 \%$ of the estimated values shows marginally overestimated thus conservative results are obtained. The remaining $36 \%$ results show lesser estimated values which can be attributed to the inaccuracy in evaluating the soil properties and the heterogeneous and anisotropic nature of the soil. It can also be observed from the results of pile no. 6 and 7, both of which from a common project in Egypt that, the ratio of measured to actual pile head deflection is 6.45 and 7.17 respectively. Thus, there is consistency in both the results in identical soil conditions, however the reason for such large values of estimated pile head deflection can be attributed to the variation in actual soil elastic modulus within top $5 \mathrm{~m}$ depth, as the $E_{s}$ value is based on the average value of top $5 \mathrm{~m}$ soil strata below the pile head.
Table -1: Details of pile head deflection

\begin{tabular}{|c|c|c|c|c|c|c|}
\hline $\begin{array}{l}\dot{0} \\
\frac{0}{2} \\
\frac{0}{\tilde{n}}\end{array}$ & 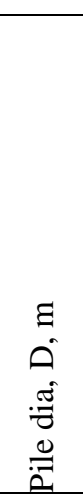 & 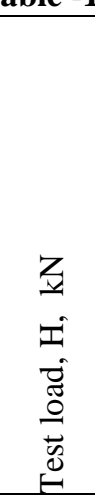 & 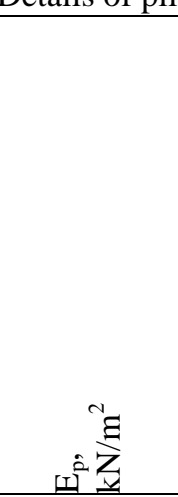 & $\underset{\underline{Z}}{\stackrel{N}{Z}}$ & 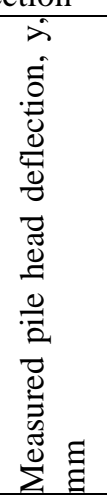 & 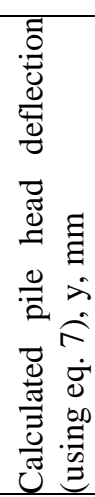 \\
\hline 1 & 0.60 & 93.5 & 27386128 & 40800 & 2.66 & 2.12 \\
\hline 2 & 0.60 & 172.5 & 27386128 & 41400 & 4.84 & 6.01 \\
\hline 3 & 0.60 & 124.7 & 27386128 & 42000 & 2.44 & 3.33 \\
\hline 4 & 0.45 & 72.7 & 27386128 & 42000 & 2.66 & 2.66 \\
\hline 5 & 0.45 & 36.4 & 27386128 & 19200 & 1.20 & 3.04 \\
\hline 6 & 0.60 & 75.0 & 29580399 & 18432 & 0.87 & 5.61 \\
\hline 7 & 0.60 & 100.0 & 29580399 & 18432 & 1.29 & 9.25 \\
\hline 8 & 0.60 & 250.0 & 27386128 & 84906 & 7.30 & 3.36 \\
\hline 9 & 0.60 & 190.0 & 27386128 & 120656 & 4.57 & 1.14 \\
\hline 10 & 0.40 & 102.0 & 44721360 & 31033 & 16.22 & 10.61 \\
\hline 11 & 0.40 & 260.0 & 44721360 & 34500 & 40.36 & 45.13 \\
\hline 12 & 0.51 & 224.0 & 199948000 & 27450 & 43.10 & 27.14 \\
\hline 13 & 0.51 & 255.0 & 199948000 & 15000 & 92.95 & 95.55 \\
\hline 14 & 0.50 & 266.9 & 29580399 & 25777 & 10.70 & 45.27 \\
\hline
\end{tabular}

This error can also be eliminated by introducing additional variables related to soil properties in the mathematical formulation based on some more field data. It shall also be noted that all the piles in this study were behaving as long piles with the pile head free against rotation and deflection and hence equation (7) is applicable only for the long piles under the free head condition. Separate field tests and the analysis are required for the pile behaving as a short pile and fixed head pile due to its dissimilar behavior.

\section{CONCLUSION}

A mathematical tool such as dimensional analysis can be used to solve soil-structure interaction problems with a relatively acceptable degree of accuracy for a heterogeneous and anisotropic material like soil.

As the soil - pile analysis is one of the complex problems in geotechnical engineering, dimensional analysis proves its versatile applications to solve complex problems using simple equations.

This study can be further extended using more and more field pile test data to model the soil pile behavior with more precision. 


\section{SYMBOLS}

$\beta_{1}, \beta_{2, \ldots .} \beta_{\mathrm{N}}$

constants

$\mathrm{D}$

$\mathrm{D}_{\mathrm{p}}$

D.G.s

$\mathrm{E}_{\mathrm{p}}$

$\mathrm{E}_{\mathrm{s}}$

$\mathrm{H}$

L

$\mathrm{m}$

M

n

$\mathrm{N}$

Q

$\mathrm{R}$

$\mathrm{T}$

V

$\mathrm{y}$

$\pi_{2 \ldots \ldots . . .} \pi_{\mathrm{N}}$
Pile diameter in meter

set of independent primary dimensions

dimensionless groups represented by $\pi_{1}$,

Pile elastic modulus in $\mathrm{kN} / \mathrm{m}^{2}$

Soil elastic modulus in $\mathrm{kN} / \mathrm{m}^{2}$

Lateral load at the pile head in $\mathrm{kN}$

length-dimension

number of independent primary

dimensions in $\mathrm{D}_{\mathrm{p}}$

mass-dimension

number of variables or parameters

(n-m); number of dimensionless groups

set of repeating variables

set of variables in $\mathrm{V}$ which have dimensions totally distinct from each other time-dimension

set of independent and dependent parameters involved in the phenomenon pile head deflection in meter

\section{REFERENCES}

[1]. ASTM Standard D 3966. 1990. Standard test Method for Piles under Lateral Loads, Annual Book of ASTM Standards, ASTM International, West Conshohocken, PA.

[2]. Birid, K. C. 2003. Critical Assessment of Unconfined Compressive Strength of Rock using Modified Buckingham Method, Proceedings of Indian Geotechnical Conference IGC, Roorkee chapter, India,Vol-I, Dec. 18-20, 2003, pp. 529-534.

[3]. Butterfield, R. 1999. Dimensional Analysis for Geotechnical Engineers, Geotechnique, Vol. 49, No. 3, pp. 357-366.

[4]. Phatak, D. R. and Dhonde, H. B. 2003. Dimensional Analysis of Reinforced Concrete Beams Subjected to Pure Torsion, J. Structural Engineering, Vol. 129, Issue 11, pp. 1559-1564.

[5]. Phatak, D. R. and Dhonde, H. B., 2000. Discussion of Behavior of Five Large Spread Footings in Sand, J. Geotechnical \& Geoenvironmental Engineering, Vol. 126, Issue 10, pp. 940-942.

[6]. Phatak, D. R., Pathak, S. R. and Birid, K. C. 2004.

Estimation of Phreatic Line using Dimensional Analysis, paper no. 2.76, Proceedings: Fifth International Conference on Case Histories in Geotechnical Engineering, New York, NY, April 13-17, 2004, pp. 1-6.

\section{BIOGRAPHIES}

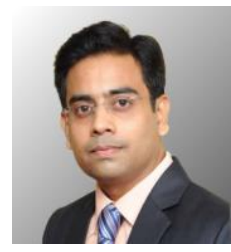

Kedar Birid: He has a masters degree from University of Pune and has more than 15 years of diverse experience in geotechnical engineering. He has been associated with various multinational geotechnical contractors, consultants and the owners in the past. Currently he is working with Toyo Engineering India Pvt. Ltd. as a geotechnical expert. His research areas include application of dimensional analysis, study of the feasibility and applications of field and lab testing in geotechnical engineering. 